О. В. Рибак

Державний університет «Одеська політехніка», Одеса, Україна

\title{
СИСТЕМА АВТОМАТИЗОВАНОГО ПРОЕКТУВАННЯ ДЛЯ ВИЗНАЧЕННЯ ОПТИМАЛЬНИХ ПАРАМЕТРІВ ШЛІФУВАННЯ ПОКРИТТІВ
}

\begin{abstract}
Анотація. При пошуку оптимальних параметрів обробки плазмових покриттів існуючі САПР призводять до значних відхилень через те, що не враховують зменшення втрат матеріалу у якості критерію оптимальності та не забезпечують умови бездефектної обробки поверхні. Таким чином, при розробці САПР ТП шліфування плазмових покриттів необхідно передбачити підсистеми аналізу характеристик проектованого об'єкта, моделювання полів температур та напружень в процесі обробки, оптимізації параметрів шліфування та перевірки критеріїв міцності і руйнування при досягненні заданої шорсткості поверхні. У даній статті побудована структура такої САПР та наведено користувацький інтерфейс відповідного програмного комплексу. Для визначення оптимальних параметрів шліфування покриттів застосовується еволюційний пошук на множині допустимих розв'язків, сформованій на основі технічних характеристик шліфувального кругу і верстата. Отримані результати у вигляді набору розв'язків задачі оптимізації, графіків та протоколу роботи алгоритму відображаються через інтерфейс користувача. Проведені експерименти підтвердили зростання продуктивності шліфування плазмових покриттів і зменшення кількості бракованих виробів при застосуванні параметрів обробки, визначених у представленій САПР.
\end{abstract}

Кл юч ов і сл ов а: система автоматизованого проектування, плазмові покриття, шліфування, програмний інтерфейс, алгоритм пошуку.

\section{Вступ}

Системи автоматизованого проектування є одним 3 найбільш перспективних напрямків підвищення ефективності технологічних процесів. Втім, спроби використання сучасних САПР для оптимізації процесу фінішної обробки деталей з плазмовим покриттям призводять до низки труднощів, пов'язаних з особливостями шліфувальних операцій для плазмових покриттів. Аналіз принципів роботи найпоширеніших САПР $[1,2]$ виявив, що математичний апарат, на якому грунтується їхнє програмне забезпечення, базується на методі скінченних елементів. Такий підхід спрощує техніку розрахунку, але спричинює суттєві похибки при проектуванні гетерогенних об'єктів, таких як плазмові покриття 3 композиційних матеріалів, що мають спадкові неоднорідності та різні властивості покриття і основи. Існуючі САПР процесу шліфування створювались на основі математичних моделей обробки деталей, що мають суцільну структуру, відтак, їхнє використання при шліфуванні деталей з плазмовим покриттям може призводити до значних відхилень. В процесі шліфування високі значення температур та напружень, що виникають в нанесеному шарі, можуть зумовити утворення поверхневих та структурних дефектів, таких як шліфувальні припалення та тріщини, фазові перетворення матеріалу покриття та відшаровування нанесеного шару від основи [3]. Таким чином, для визначення оптимальних параметрів шліфування плазмових покриттів необхідно створити систему автоматизованого проектування, що враховуватиме особливості структури нанесеного матеріалу, його пористість та включення інших фаз, а також виходитиме $з$ критеріїв оптимальності, що були сформульовані у попередніх роботах $[4,5]$.

Метою статті $\epsilon$ розробка структури системи автоматизованого проектування для вибору параметрів шліфування плазмових покриттів, іiі практич- на реалізація та представлення відповідних інтерфейсів результатів проектування.

\section{Основна частина}

Робота системи автоматизованого проектування процесу шліфування плазмових покриттів спирається на результати оптимізації технологічних параметрів обробки нанесеного шару, а також моделювання температурного поля та напруженодеформованого стану деталей з покриттям, оскільки високі значення температур та напружень впливають на утворення поверхневих та структурних дефектів оброблюваної поверхні. Формулювання умов поставленої задачі вимагає визначення характеристик нанесеного шару покриття, що залежать від параметрів плазмового напилювання, вибору режиму використання змащувально-охолоджуючих рідин при шліфуванні, розрахунку міцності зчеплення покриття з основним матеріалом деталі тощо. Таким чином, програмний комплекс САПР шліфування плазмових покриттів включатиме підсистеми аналізу характеристик проектованого об'єкта, моделювання полів температур та напружень в процесі обробки, оптимізації параметрів шліфування та перевірки критеріїв міцності і руйнування при досягненні заданої шорсткості поверхні. Послідовність задач, які повинна вирішувати розроблена САПР, наведена на рис. 1.

Моделювання температурного поля деталі 3 покриттям $є$ окремою задачею, яка може вирішуватись як 3 метою оптимізації процесу шліфування, так і для перевірки умов бездефектної обробки поверхні. Крім того, слід передбачити окремий блок для визначення рекомендованих параметрів шліфувального кругу, адже композиційні плазмові покриття можуть включати надтверді фази, що накладатиме особливі вимоги на абразивний матеріал при їхній обробці. Необхідна для розрахунків інформація щодо вибору шліфувального кругу, властивостей 
матеріалу покриття та технічних можливостей шліфувального верстата зберігатиметься у відповідних базах даних САПР ТП шліфування плазмових покриттів.

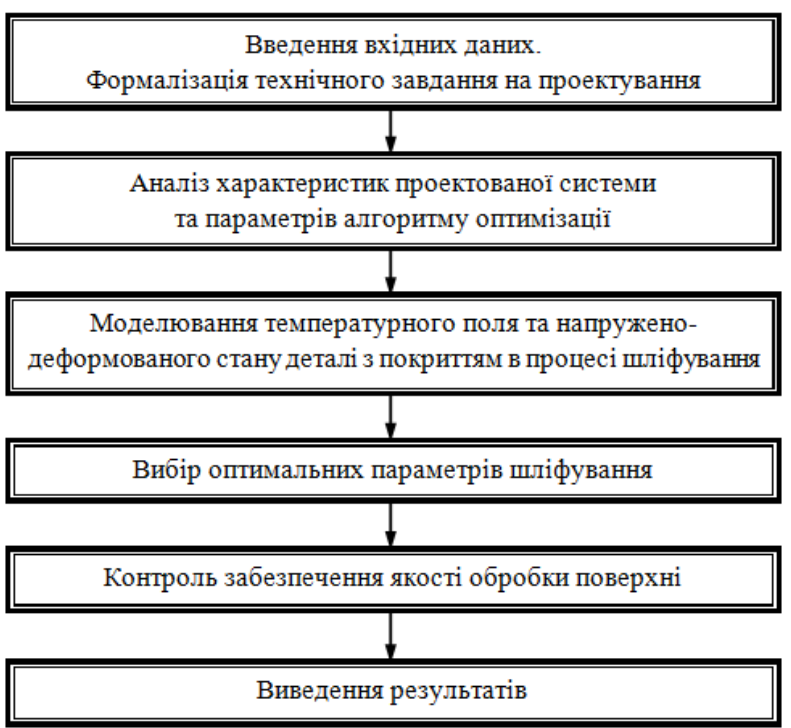

Рис. 1. Послідовність задач до виконання в межах розробленої САПР ристик шліфувального верстата. Максимальні та мінімальні значення швидкості обробки і глибини шліфування задають діапазон значень для вектору параметрів обробки, а ціна поділки шкали визначає дискретність цього діапазону для кожної із зазначених величин. Схема бази даних, яка містить інформацію про можливості шліфувальних верстатів щодо вибору параметрів режиму обробки, представлена на рис. 2.

Після задання вхідних даних, частина 3 яких вводиться вручну, частина - шляхом вибору відповідного варіанту зі списку значень, що містяться у базі даних, відбувається аналіз характеристик проектованої системи: встановлюються граничні умови для задачі термонапруженості, проводяться розрахунки величин, необхідних при моделюванні, оптимізації та контролі якості обробки поверхні. Моделювання температурного та деформаційного полів залежить від параметрів шліфування, які змінюються в процесі еволюційного пошуку, а система обмежень для забезпечення якості обробки вимагає постійної перевірки та корекції отриманих результатів. На рис. 3 представлений взаємозв'язок між окремими модулями, які слід передбачити в САПР ТП шліфування плазмових покриттів.

Формування множини допустимих розв'язків задачі оптимізації шліфування плазмових покриттів відбувається на підставі аналізу технічних характе-

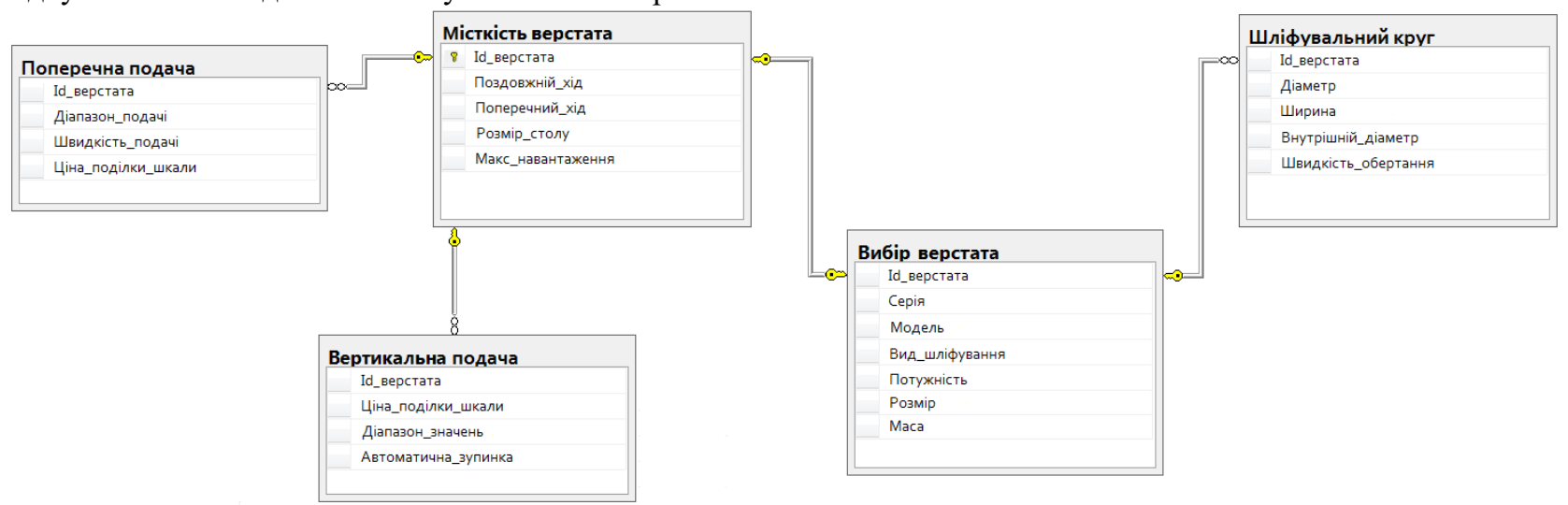

Рис. 2. Схема бази даних «Вибір шліфувального верстата»

При розробці структури САПР підсистему моделювання процесу шліфування плазмових покриттів, підсистему вибору оптимальних параметрів шліфування та підсистему контролю було об'єднано в програмному пакеті модулів, у межах кожного 3 яких передбачений аналіз необхідних для вирішення певної задачі характеристик. Отримані результати у вигляді набору розв'язків задачі оптимізації, графіків та протоколу роботи алгоритму відображаються через інтерфейс користувача. На рис. 4 наведена загальна структура розробленої САПР шліфування плазмових покриттів.

Підсистема вибору оптимальних параметрів процесу шліфування покриттів реалізована в межах розробленої САПР на основі модифікованого генетичного алгоритму, запропонованого у попередніх дослідженнях, присвячених даній проблематиці [6].
За допомогою розробленого програмного комплексу можна визначити рекомендовані характеристики шліфувального кругу, здійснити моделювання процесу обробки, знайти оптимальні параметри шліфування, ознайомитися 3 інструкціями щодо функціонування представленої САПР у розділі «Довідка», створити та зберегти протокол роботи модифікованого генетичного алгоритму.

Вікно підсистеми вибору оптимальних параметрів шліфування містить вкладки постановки задачі, представлення ходу розв'язку та графічного зображення результатів оптимізації. Введення вхідних даних для задачі оптимізації включає задання параметрів режиму напилювання та матеріалу плазмового покриття, вибору розмірів та характеристик шліфувального кругу, які можуть завантажуватись 3 модулю рекомендованих параметрів, визначення 
виду шліфувального верстата та режиму охолодження. Необхідно також вказати значення шорсткості готової деталі після іï обробки і параметри модифікованого генетичного алгоритму оптимізації. Вікно введення вхідних даних задачі вибору опти- мальних параметрів технологічного процесу при шліфуванні деталей з плазмовим покриттям наведено на рис. 5. Результати еволюційного пошуку оптимальних параметрів обробки викладені у вікні представлення ходу розв’язку задачі (рис. 6).

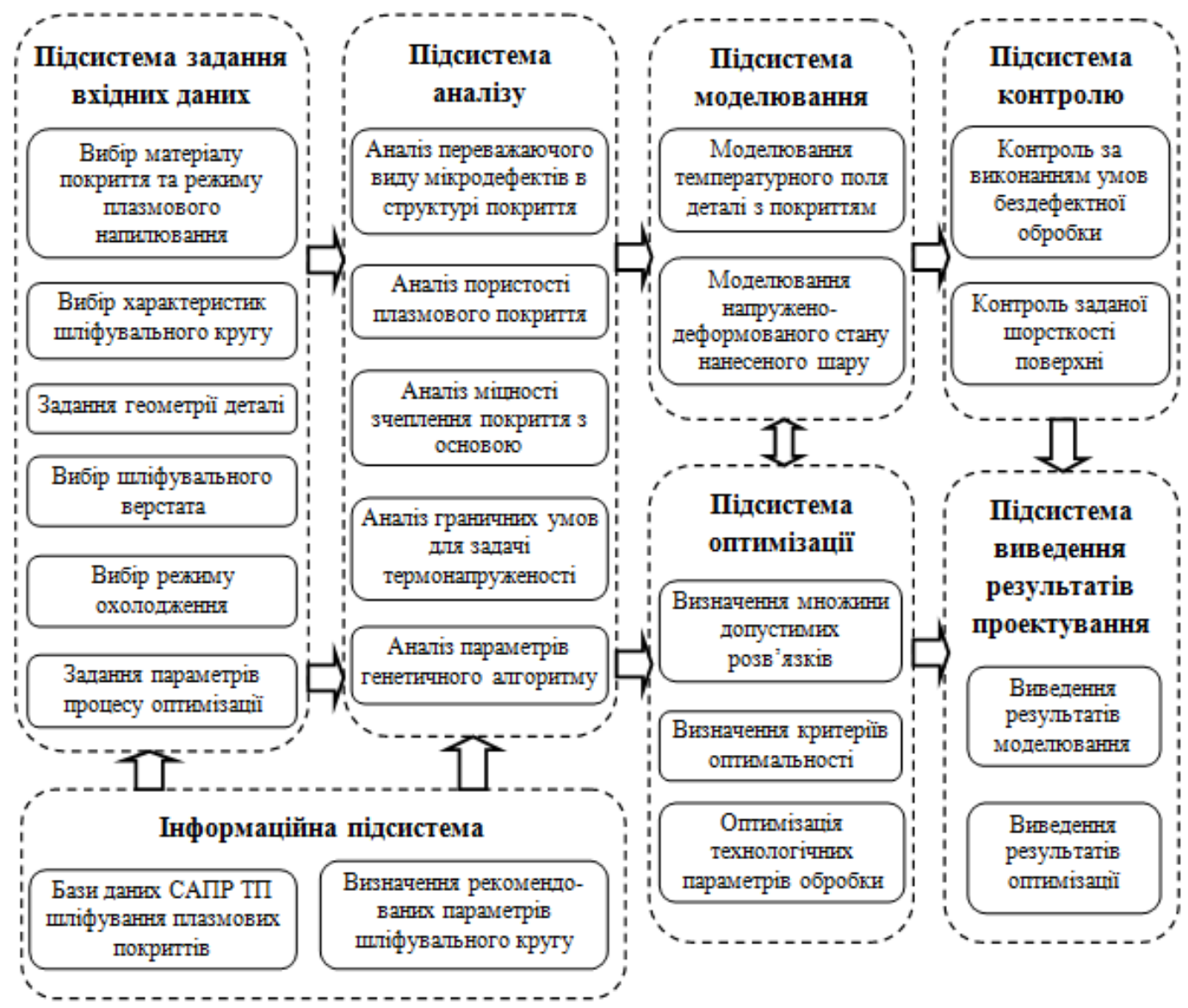

Рис. 3. Схема взаємозв'язків між модулями в САПР ТП шліфування плазмових покриттів

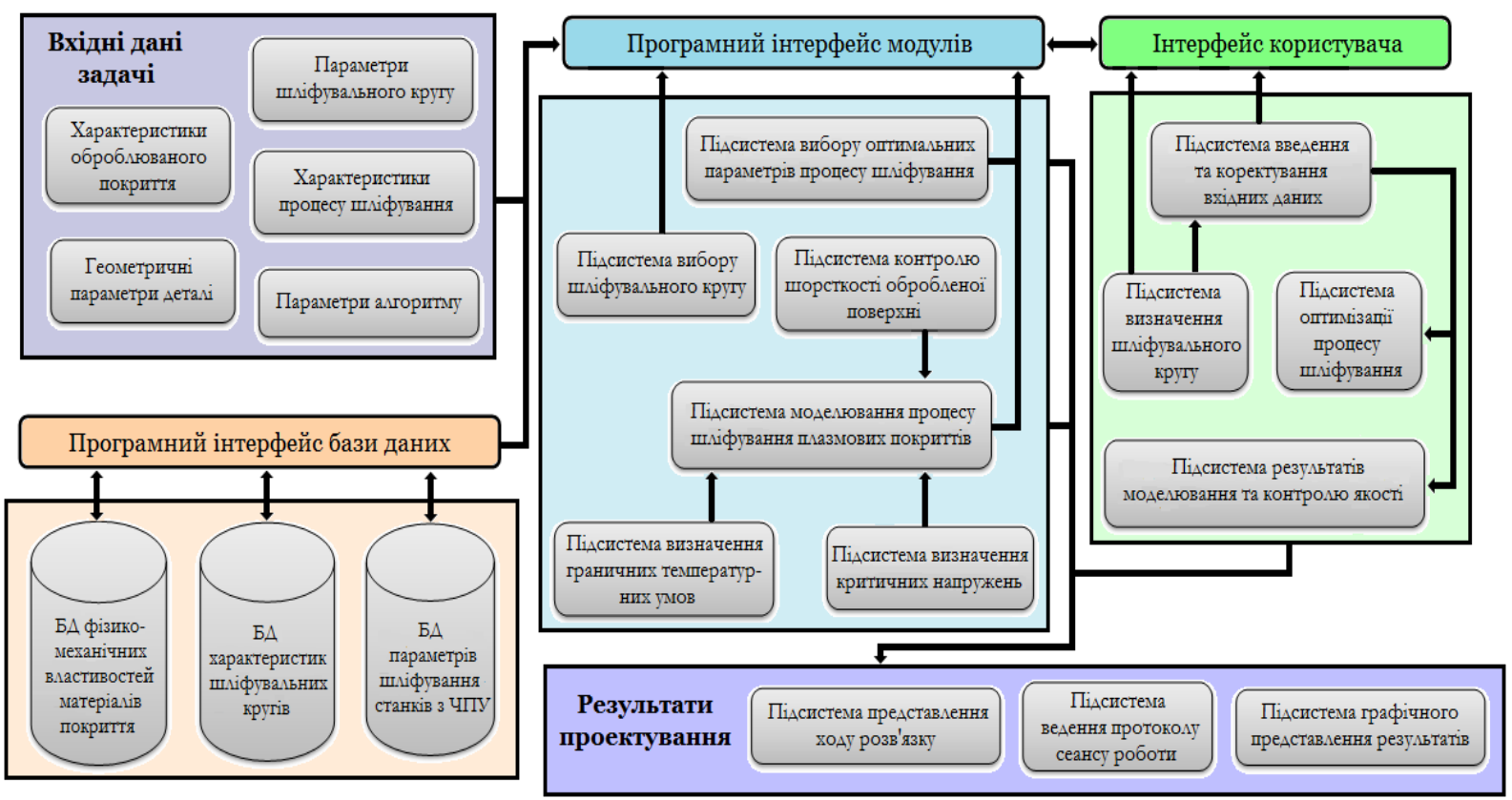

Рис. 4. Структура САПР шліфування плазмових покриттів 


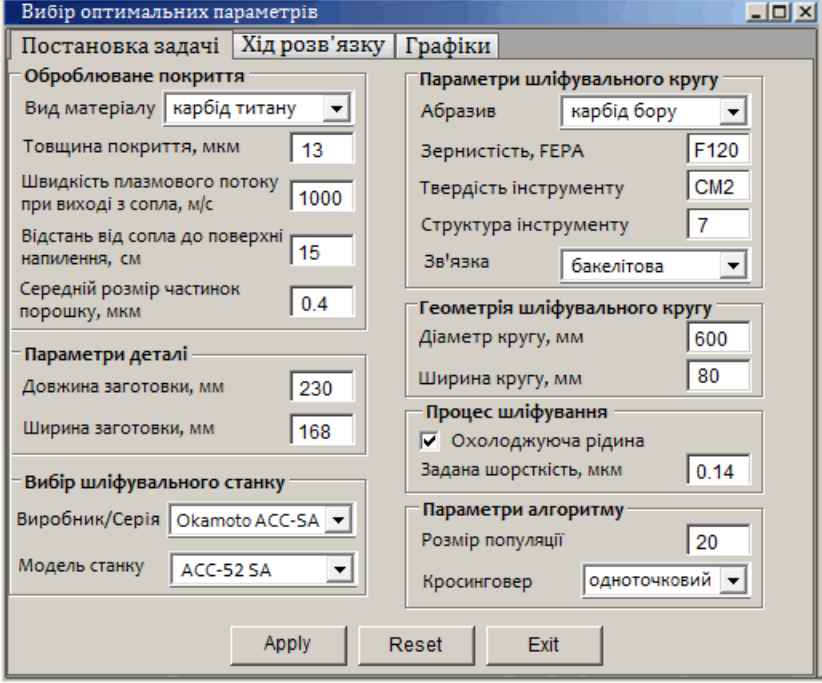

Рис. 5. Вікно введення початкових даних для пошуку оптимальних параметрів шліфування

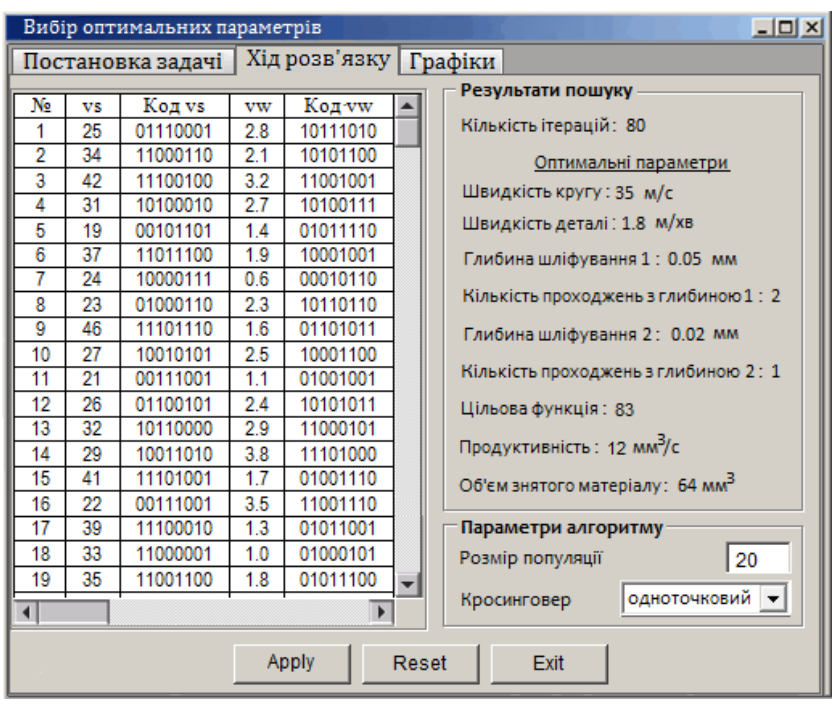

Рис. 6. Вікно представлення ходу розв’язку

Покроковий процес роботи алгоритму дозволяє проаналізувати динаміку зростання функції присто- сованості для кожної наступної популяції. Значення змінних параметрів викладені разом з їннім генотипом, отриманим шляхом бінарного кодування. 3 огляду на те, що оптимізація проводиться для комплексного критерію, поряд 3 результуючою цільовою функцією також вказані продуктивність та об'єм знятого матеріалу, що залежить від припуску на шліфування.

Проаналізувати графік зростання значення найбільшої пристосованості для кожної популяції при переході від однієї ітерації алгоритму до іншої дозволяє вікно графічного зображення результатів оптимізації (рис. 7).

На графіку представлена залежність комплексного критерію оптимальності від номеру популяції в процесі еволюційного пошуку. Поряд наведено точні значення максимальної функції пристосованості для кожної ітерації ходу розв'язку задачі. Зберегти результати роботи модифікованого генетичного алгоритму можна, створивши відповідний протокол (рис. 8).

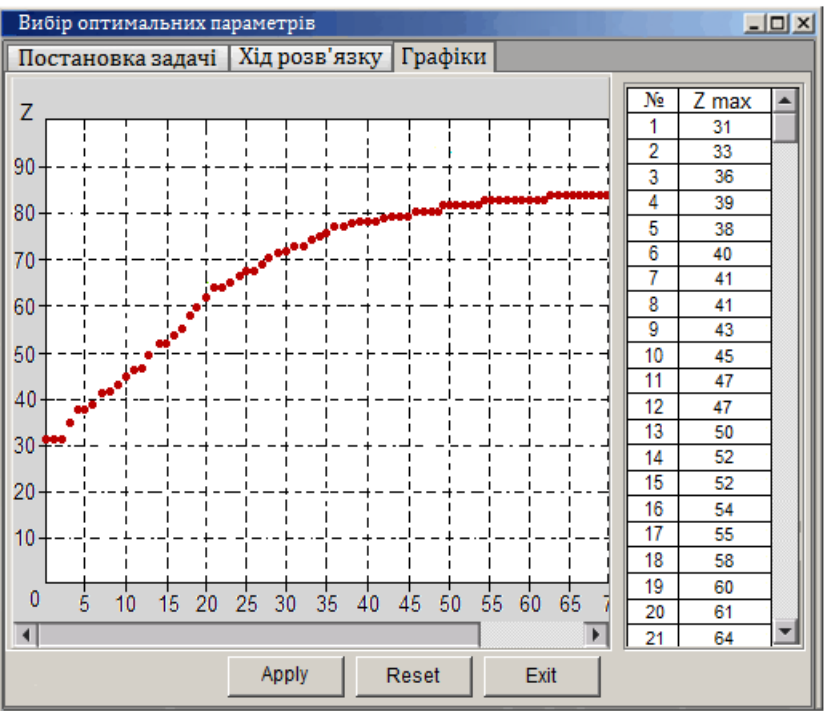

Рис. 7. Вікно графічного зображення результатів оптимізації

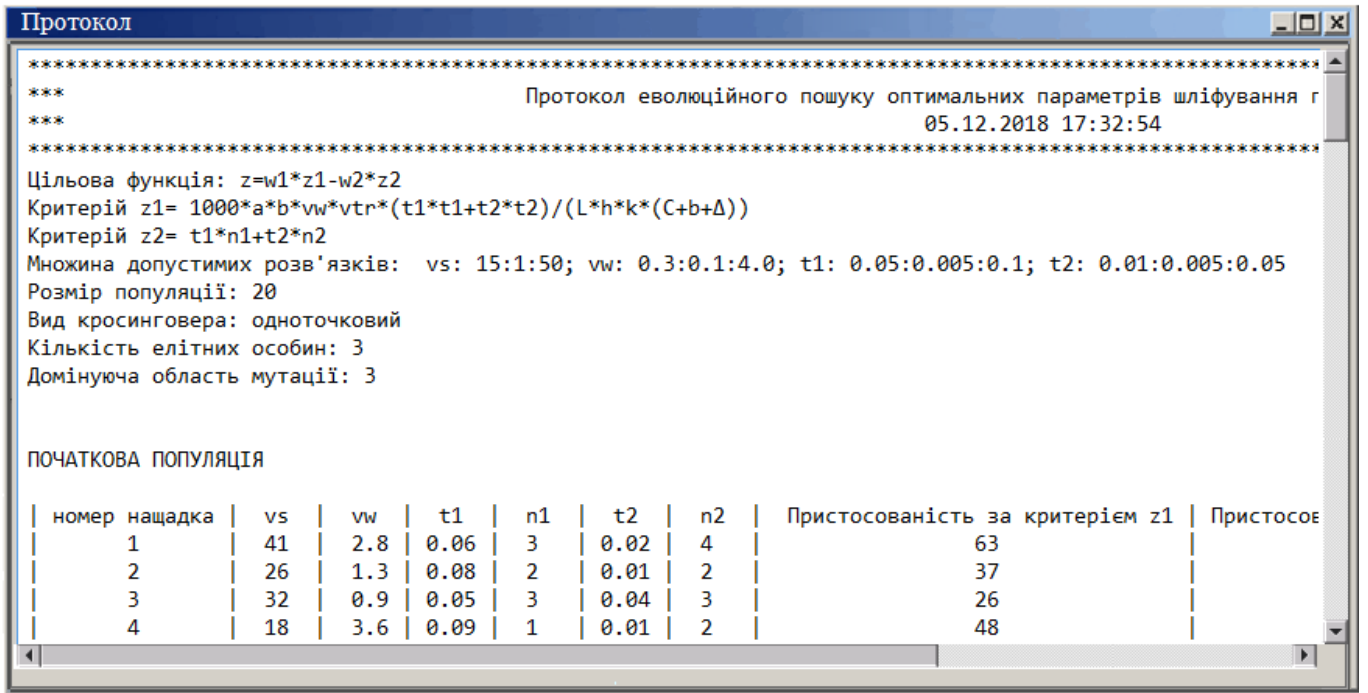

Рис. 8. Протокол роботи модифікованого генетичного алгоритму 
Протокол еволюційного пошуку оптимальних параметрів шліфування при обробці плазмових покриттів містить значення змінних технологічних параметрів, що формують особини популяції, їхню пристосованість за частковими критеріями та комплексним критерієм оптимальності. Також вказано діапазон допустимих розв'язків для змінних параметрів та основні характеристики оптимізаційного процесу. 3 наведених результатів можна зробити висновок, що загальний розв'язок представленої задачі $€$ компромісним значенням для кожного 3 часткових критеріїв оптимальності.

Продуктивність процесу обробки плазмових покриттів при виборі оптимальних параметрів шліфування, визначених за допомогою розробленої САПР, порівнювалась із розрахунковими результатами продуктивності, отриманими для типових параметрів режиму обробки.

Проведені експерименти підтвердили зростання продуктивності шліфування плазмових покриттів при застосуванні параметрів обробки, визначених у представленій САПР у порівнянні з типовою продуктивністю розглянутого технологічного процесу. Випробування також дозволили зменшити кількість деталей зі шліфувальними дефектами при обробці плазмових покриттів.

\section{Висновки}

На основі математичної моделі термомеханічного стану, умов бездефектної обробки та модифікованого методу еволюційного пошуку розроблено САПР технологічного процесу шліфування плазмових покриттів, що складається з:

блоку задання вхідних даних,

інформаційної підсистеми,

підсистем аналізу, моделювання, оптимізації та контролю параметрів режиму шліфування.

Випробування створеної САПР проводилося для визначення параметрів режиму обробки плазмових покриттів на основі композиційних матеріалів 3 надтвердою фазою, для яких вдалося зменшити число поверхневих та структурних дефектів та визначити оптимальні параметри шліфування.

Отримано розв'язок задачі оптимізації для різних значень вхідних даних, процес еволюційного пошуку проаналізовано завдяки графічному зображенню результатів оптимізації та покроковому представленню ходу розв'язку.

Дослідження розробленої системи САПР при шліфуванні деталей дозволяє знизити кількість бракованих виробів при збільшенні продуктивності технологічного процесу обробки.

\section{СПИСОК ЛІТЕРАТУРИ}

1. Лазарєва Д.В. Математичні моделі та чисельно-аналітичні методи аналізу в САПР складних асиметричних технічних систем: дис. канд. техн. наук. Одеса: ОНПУ. - 2015. - 192 с.

2. Бажанова А.Ю. Моделі та методи аналізу пружно-дисипативних систем в САПР: дис. канд. техн. наук. Одеса: ОНПУ. - 2015. - $147 \mathrm{c}$

3. Usov A.V., Tonkonogyi V.M., Dašić P.V., Rybak O.V. Modelling of Temperature Field and Stress-Strain State of the Workpiece with Plasma Coatings during Surface Grinding // Machines. MDPI, Basel, Switzerland. - 2019. - Vol. 7, Is. 1. $15 \mathrm{p}$.

4. Тонконогий В.М., Рибак О.В. Вибір параметрів шліфування плазмових покриттів при багатокритеріальній оптимізації технологічного процесу // Сучасні технології в машинобудуванні. Харків: НТУ "ХПІ". - 2018. - Вип. 13. C. $60-68$

5. Рибак О.В. Математичне моделювання, аналіз та оптимізація в САПР технологічного процесу шліфування плазмових покриттів: дис. канд. техн. наук. Одеса: ОНПУ, 2019. - 162 с.

6. Tonkonogyi V., Dašić P., Rybak O., Lysenko T. Application of the Modified Genetic Algorithm for Optimization of Plasma Coatings Grinding Process // Springer Nature Switzerland AG 2020. I. Karabegović (Ed.): NT 2019, Lecture Notes in Networks and Systems, 76. - P. 199-211.

\section{Computer-aided design system for determining optimal parameters of the coatings grinding}

\section{O. Rybak}

Abstract. While searching for optimal parameters of plasma coatings grinding, available CAD systems produce significant deviations due to the fact that they neither take into account reducing losses of the material as an optimality criterion nor meet the conditions of zero-defect surface processing. Therefore the developed plasma coatings grinding CAD system should include modules of the designed object characteristics analysis, temperature fields and stresses modelling, grinding parameters optimization and checkup strength and fracture criteria when the required surface roughness is reached. In this paper the structure of such a CAD system is built and the user interface of the according programming appliance is presented. In order to determine optimal parameters for the coatings grinding process, an evolutionary search is carried out on a set of feasible solutions formed on the basis of the features of plasma coatings materials and technical characteristics of the grinding wheel and the grinding machine. Obtained results consisting sets of optimization problem solutions, plots and the algorithm performance protocol are displayed through the user interface. Practical experiments that were carried out during this research confirm an increased productivity of the plasma coatings grinding process and reduced number of defective parts when applying grinding parameters determined in the designed CAD system.

Keywords: computer-aided design system, plasma coatings, grinding, programming interface, search algorithm. 